\title{
Erratum
}

\section{Erratum: Moehle et al., "LRRK2 Inhibition Attenuates Microglial Inflammatory Responses"}

In the article, "LRRK2 Inhibition Attenuates Microglial Inflammatory Responses," by Mark S. Moehle, Philip J. Webber, Tonia Tse, Nour Sukar, David G. Standaert, Tara M. DeSilva, Rita M. Cowell, and Andrew B. West, which appeared on pages 1602-1611 of the February 1, 2012 issue, the representative image for LRRK2-shRNA-B treated microglia in Figure $6 B$ was duplicated from the first image in Figure 6D. This error does not affect the conclusions of the paper. The corrected figure appears below.

\section{A}

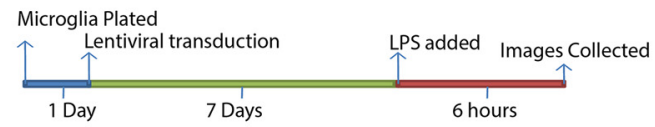

B -LPS
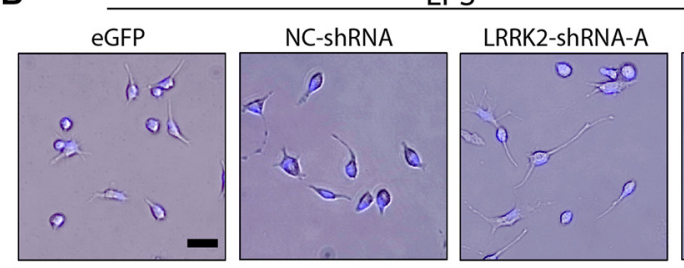

LRRK2-shRNA-B

C

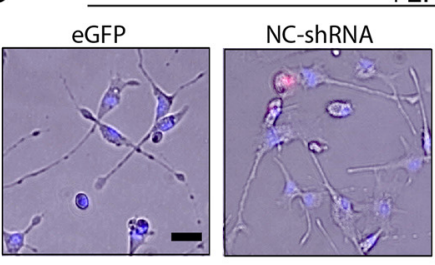
LPS

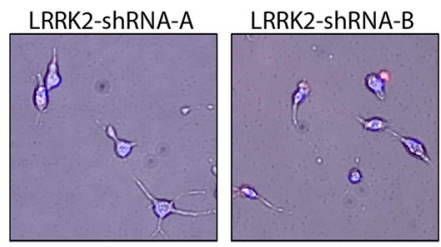

D

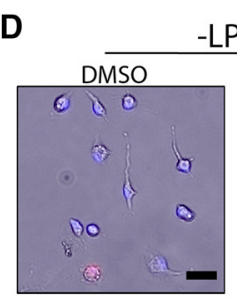

E
LPS

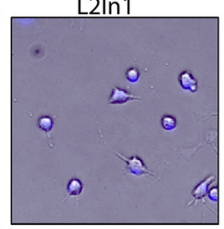

e

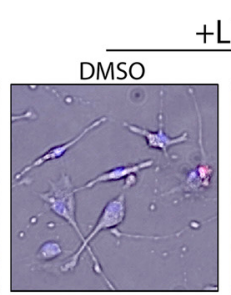

$\mathbf{F}$

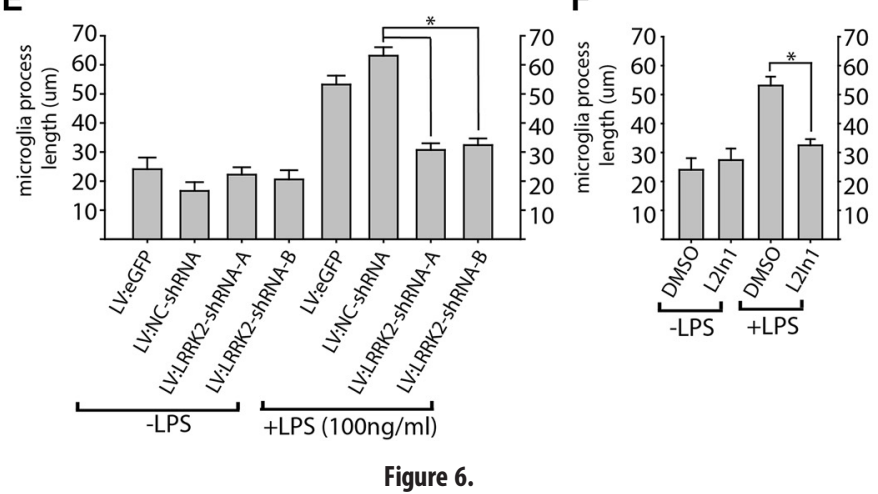

